"Influence of demographic factors on the entrepreneurial intentions of university students in Oman"

$\begin{array}{ll} & \text { Mohammad Ahmar Uddin } \\ \text { SUTHORS } & \text { Samir Mohammad } \\ & \text { Sammami Hamma }\end{array}$

Mohammad Ahmar Uddin, Shariq Mohammad and Samir Hammami (2016).

ARTICLE INFO Influence of demographic factors on the entrepreneurial intentions of university students in Oman. Investment Management and Financial Innovations, 13(1-1), 215-220. doi:10.21511/imfi.13(1-1).2016.08

DOI http://dx.doi.org/10.21511/imfi.13(1-1).2016.08

RELEASED ON Friday, 08 April 2016

JOURNAL "Investment Management and Financial Innovations"

FOUNDER LLC "Consulting Publishing Company "Business Perspectives"

NUMBER OF REFERENCES

0

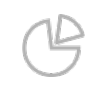

NUMBER OF FIGURES

0

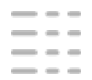

NUMBER OF TABLES

0

(C) The author(s) 2022. This publication is an open access article. 
Mohammad Ahmar Uddin (Oman), Shariq Mohammad (Oman), Samir Hammami (Oman)

\title{
Influence of demographic factors on the entrepreneurial intentions of university students in Oman
}

\begin{abstract}
This paper aims to examine the relationship of four critical demographic factors, namely, Father's occupation, Gender, Experience and Level of education on the entrepreneurial intention of Omani university students. The study uses a structured questionnaire to conduct a survey which is administered to the students of Dhofar University. The data collected are analyzed and it is found that there is a high level of intentions among students to start entrepreneurial ventures. Moreover, demographic factors are found to be influencing the entrepreneurial intention. Among the demographic factors experience is found to have the maximum influence on the entrepreneurial interest. The results suggest a need to provide students with on job training for gaining experience along with their educational programs. As an increase in experience will lead to a higher entrepreneurial intention of students and thus the likelyhood of a student becoming an entrepreneur will increase. Furthermore, universities and government should promote entrepreneurship training programs taking into account the Father's occupation, Gender, Experience and Education Levels of students.
\end{abstract}

Keywords: demographic, Oman, entrepreneurial intention, survey.

JEL Classification: J10, O53, M13, C83.

\section{Introduction}

Entrepreneurship generates significant economic opportunities for an individual which in turn helps in the economic development of a country. Entrepreneurial intentions (hereafter, EI) are important as they are antecedent for new entrepreneurship ventures (Kolvereid, 1996; Linan, Cohard \& Cantuche, 2005). Previous studies have highlighted the influence of Demographics on the EI (Reynolds, 1991; Stanworth et al., 1989; Wang \& Wong, 2004).

Sultanate of Oman is dependent on the hydrocarbon sector as it is a major contributor to the Gross Domestic Product (GDP). The government desires to reduce the dependence on the oil sector. Proceeds from the hydrocarbon exports have been used to diversify the economy. This has been done by promoting entrepreneurship through various funding schemes with a view to diversify the national economy through Small \& Medium Enterprises (SMEs). Currently the contribution of SMEs to the GDP is between 13-14 per cent but Oman aims to increase it to around 20 per cent of GDP by 2020 . Also for oil dependent economy such as Oman fluctuations in oil prices leads to a substantial reduction GDP (depicted in Table 1). Such economic shocks can be cushioned by promotion of entrepreneurship.

Table 1. GDP statistics of Oman (Rial Omani, Billion)

\begin{tabular}{|l|c|c|c|c|c|c|c|c|c|}
\hline \multirow{2}{*}{ Year } & \multirow{2}{*}{2010} & \multirow{2}{*}{2011} & \multirow{2}{*}{2012} & \multirow{2}{*}{2013} & \multicolumn{4}{c|}{2014} & \multicolumn{2}{c|}{2015} \\
\cline { 6 - 11 } & & & & & 2014 & 2014 & 2014 & 2014 & Q1 \\
\hline All economy & 22.6 & 26.1 & 29.4 & 30.1 & 7.6 & 15.3 & 23.6 & 31.5 & 6.5 \\
\hline \% change & 21.9 & 15.9 & 12.4 & 2.4 & 0.9 & -14.0 & 5.2 & 4.6 & -14.2 \\
\hline Oil GDP & 10.4 & 13.9 & 15.3 & 15.2 & 3.8 & 7.5 & 11.4 & 14.8 & 2.4 \\
\hline \% change & 40.7 & 33.7 & 10.5 & -0.9 & -0.2 & -0.4 & 1.4 & -2.4 & -36.8 \\
\hline Non-oil GDP & 12.2 & 14.1 & 16.0 & 17.2 & 4.3 & 8.7 & 13.6 & 18.9 & 4.4 \\
\hline \% change & 9.9 & 11.7 & 13.6 & 7.3 & 8.3 & 7.3 & 8.2 & 10.1 & 4.1 \\
\hline
\end{tabular}

Source: Economic Review of Sultanate of Oman, July 2015.

Oman has embarked on various steps to enable the youths to pursue entrepreneurship. Public Authority for Small and Medium Enterprises Development (Riyada) provides special schemes to entrepreneurs. Initiatives specially designed for youths are such as the SANAD and Al Raffd fund.

(c) Mohammad Ahmar Uddin, Shariq Mohammad, Samir Hammami, 2016. Mohammad Ahmar Uddin, Department of Accounting and Finance, Dhofar University, Oman.

Shariq Mohammad, Department of Accounting and Finance, Dhofar University, Oman.

Samir Hammami, Department of Management Information System, Dhofar University, Oman.
The promotion of entrepreneurship in Oman is in line with a worldwide trend of great interest in the proliferation of new firms hoping that they will help in the economic development and provide employment. This trend is based on the realization that the existing large businesses can no longer fulfil the increased requirements of employment and entrepreneurship will resolve problems of unemployment and economic development (Davidsson, Lindmark \& Olofsson, 1995).

This study was carried out to find out the influence of demographics on the EI of university students in Oman. In order to promote entrepreneurship in 
Oman it is important to study the various factors which can influence the decision to become an entrepreneur. Demographics have been identified as major factor influencing entrepreneurship (refer literature review). This study aims to fulfil a research gap by investigating the influence of demographics on the EI of university students in Oman. This will help policy makers and educators to support potential entrepreneurs.

\section{Literature review}

Intention towards a particular thought or idea is a forerunner to the future course of action. EI which shows the disposition towards entrepreneurship can thus be used to forecast the likelyhood of becoming an entrepreneur. Previous researchers have attributed various factors to the formation of EI. Studies such as Fini et al. (2009), Stanworth et al. (1989) have highlighted that EI is formed by demographic factors. In the context of Oman, Shariq et al. (2016) have found through factor analysis that variables such as Society, tradition and culture, financial risk, knowledge \& skills, funding, location and family support are important for entrepreneurship. Magd et al. (2016) have also highlighted the importance of entrepreneurship in Oman.

1.1. Hypotheses development. 1.1.1. Father's occupation. Studies have been carried out to observe if there is any relationship between Father's occupation and preference for entrepreneurship and employment. Previous studies have shown that self-employed parents have an impact on the self-employment choice of their children. Scott and Twomey (1988) found that respondents whose parents owned a small business showed the highest preference for selfemployment and the lowest preference for organizational employment; Brown (1990) also observed a similar phenomenon in the UK when conducting a training program to assist undergraduates in starting their own business. He found that $38 \%$ of the pre-selected students (who are very interested in starting own business) had fathers with their own businesses, which is higher than the general level. Hakim (1988) on selfemployment choice in the UK; Crant (1996) on US undergraduates and MBAs and Schiller and Crewson (1997) on self-employment choice in the US also found similar results. Therefore, we study whether Father's occupation is a key factor that influences the EI in Oman.

$H 1_{0}$ : There is no significant relationship between Father's occupation and EI of Omani university students.

Gender. There is an overrepresentation of male entrepreneurs in most countries and it is assumed that men have higher EI than women (Turker \& Selcuk, 2009). Among the demographic factors gender was found to have a pronounced influence on the EI of students. Females were found to be less entrepreneurial than males (Wang \& Wong, 2004). Lerner and Yeoshua (1996) observed that male students have stronger entrepreneurship aspirations than females. Matthews and Moser (1996) on business graduates in the US also discovered through a longitudinal study that males' interests are consistent but females' interests decline with time.

On the contrary, it has been witnessed that the selfemployment rate of women has risen in recent years. For example, in the USA percentage of women in self-employment rose from $23.7 \%$ in 1975 to $32.3 \%$ in 1990 (Devine, 1994). Therefore, there is a need to study the influence of gender on EI of university students in Oman.

$H 2_{0}$ : There is no significant relationship between Gender and EI of Omani university students.

Experience. Previous studies have shown that prior entrepreneurial experiences can not only develop individual's entrepreneurial intentions, but can also accumulate experiences and skills for future entrepreneurial activities. Also the type of work experience (government or private) also influences the EI (Kolvereid, 1996; Mazzarol et al., 1999). Whereby, those with private sector were likely to have a higher EI than their government sector counterparts. Some researches, however, indicate that the prior entrepreneurial experiences just have slight influences on individual's knowledge of entrepreneurship and have no significant impact on their entrepreneurial attitudes (Davidsson et. al., 1995). Therefore, there is a need to study the influence of experience on the EI of university students in Oman.

$\mathrm{H3}_{0}$ : There is no significant relationship between Experience and EI of Omani university students.

Level of education. Education provides opportunities in existing firms and, thus, reduces the desirability of entrepreneurship due to the opportunity cost. But so far the influence of education on EI is unclear. We have business founders, with both lower and also above average formal education. Turker \& Selcuk (2009) have stated that individuals with lower than average education have a lesser EI. Stewart et al. (1999) studied corporate managers, small business owners and entrepreneurs, and found that corporate managers were the most highly educated as compared to entrepreneurs. In contrast, Van de Ven and Schroeder (1984) found that college educated entrepreneurs were more likely to be associated with longer surviving firms and in start-ups in high technology areas.

Therefore, there is a need to study the influence of education on the EI of university students in Oman.

H40: There is no significant relationship between the level of education and EI of Omani university students. 
Table 2. Studies on Entrepreneurship and Demographics

\begin{tabular}{|l|l|}
\hline \multicolumn{1}{|c|}{ Demographics } & \multicolumn{1}{c|}{ Previous studies } \\
\hline Father's occupation & $\begin{array}{l}\text { Brown (1990), Crant (1996), Koh (1996), Schiller \& Crewson (1997), Hakim (1988), Scott \& Twomey (1988), Tkachev } \\
\text { and Kolvereid (1999), Wang and Wong (2004), Veciana, Aponte \& Urbano (2005). }\end{array}$ \\
\hline Gender & $\begin{array}{l}\text { Devine (1994), Ghazali, Ghosh \& Tay (1995), Lerner \& Yeoshua (1996), Matthews \& Moser (1996), Kourilsky and } \\
\text { Walstad (1998), Phan, Wong \& Wang (2002), Wang \& Wong (2004), Dunn (2004), Turker \& Selcuk (2009). }\end{array}$ \\
\hline Working experience & $\begin{array}{l}\text { Ghazali, Ghosh, \& Tay (1995), Kolvereid, (1996), Mazzarol et al. (1999), Kristiansen and Indarti (2004), Othman, Ghazali } \\
\text { \& Sung (2006), Uddin \& Khan (2015). }\end{array}$ \\
\hline Level of education & Stewart et al. (1999), Turker \& Selcuk (2009), Van de Ven and Schroeder (1984). \\
\hline
\end{tabular}

\section{Methodology}

Primary data were used for this study. Data were collected using a self-administered questionnaire from 300 students of Dhofar University, OMAN. Dhofar University is among the top ten higher educational institutions of Oman and is the only university in the Dhofar region of Oman. The data collected were statistically tested for relationship between demographic factors and EI. The independent variables consist of Father's Occupation, Gender, Experience and Level of Education. Due to lack of similar studies in Oman the questionnaire was developed taking into consideration the literature review of previous international studies on EI. EI, the dependent variable, is measured by responses to three questions (Starting my own business is attractive. Entrepreneurship is a highly desirable career. It is better to be founder of a new company than to become manager of an existing one) using a
5 point Likert-scale. To test the four hypotheses, Correlation test is applied. The following coding has been used for the independent variables:

- Father's occupation (Salaried-1, Business-2).

- Gender (Male-1, Female-2).

- Experience (No-1, Yes-2).

- Level of education (Pre University-1, Diploma2, Graduate-3 and Masters-4).

\section{Results}

Responses to the questionnaires have been depicted in Table 2. $56 \%$ of students intend to become entrepreneurs. Males' respondents were 39\%, where females' were $61 \%$. Students with business as Father's occupation were $62 \%$ while salaried were $38 \%$. Only $31 \%$ of students had some experience. The Level of education was as follows: Pre-university - 20\%, Diploma $-27 \%$, Graduate $-41 \%$, and Masters $-12 \%$.

Table 3. Profile of respondents $(\mathrm{N}=300)$

\begin{tabular}{|l|l|l|l|l|}
\hline Intention & Yes $-56 \%$ & No $-44 \%$ & & \\
\hline Father's occupation & Salaried $-38 \%$ & Business $-62 \%$ & & \\
\hline Gender & Males $-39 \%$ & Females $-61 \%$ & & \\
\hline Experience & Yes $-31 \%$ & No $-69 \%$ & & \\
\hline Level of education & Pre University - 20\% & Diploma $-27 \%$ & Graduate $-41 \%$ & Masters $-12 \%$ \\
\hline
\end{tabular}

Statistical test. The list of independent variables significant relationship between Father's along with their correlation has been depicted in occupation, Gender, Experience and Education Table 3. The results show that there is a with the EI.

Table 4. Correlation analysis

\begin{tabular}{|c|c|c|c|c|c|}
\hline & Father's occupation & Gender & Experience & Level of education & Entrepreneurial intention \\
\hline Father's occupation & 1 & & & & \\
\hline Gender & -0.044 & 1 & & & \\
\hline Experience & 0.435 & -0.028 & 1 & & \\
\hline Level of education & 0.453 & 0.164 & 0.266 & 1 & \\
\hline Entrepreneurial intention & $0.283^{* *}$ & $-0.296^{\star *}$ & $0.674^{* *}$ & $-0.301^{* *}$ & 1 \\
\hline $\mathrm{R}$ & R square & \multicolumn{2}{|c|}{ Adjusted R square } & \multicolumn{2}{|c|}{ Std. error of the estimate } \\
\hline $0.736^{\mathrm{a}}$ & 0.542 & \multicolumn{2}{|c|}{0.536} & \multicolumn{2}{|c|}{0.339} \\
\hline ANOVAb $^{b}$ & Sum of squares & Df & Mean square & $\mathrm{F}$ & Sig. \\
\hline Regression & 40.047 & 4 & 10.012 & 87.191 & 0.000 \\
\hline Residual & 33.873 & 295 & 0.115 & & \\
\hline Total & 73.920 & 299 & & & \\
\hline
\end{tabular}

Notes: ${ }^{* *}$ Correlation is significant at the 0.01 level (2-tailed). a. Predictors: (Constant), Experience, Father's occupation, Level of education, Gender. $b$. Dependent variable: Entrepreneurial intention. 
Table 3 shows the value of the $\mathrm{R}$ square as 0.542 , which indicates a good level of prediction. The Fratio in the ANOVA test shows that overall regression model is a good fit for the data. The independent variables Father's occupation, Gender, Experience and the Level of education can predict the dependent variable significantly $[F(4,295)=$ 87.191, $\mathrm{p}<0.001]$.

\section{Discussion}

Entrepreneurial intention. It was found that majority of the students $(56 \%)$ have intention to become an entrepreneur. The results are within the range of previous studies conducted on EI of university student. Though the findings differ as per the region and with time, but the lowest EI was found to be $24.6 \%$ (Scott \& Twomey, 1988) while highest value was 90\% (Timmons, 1994).

Father's occupation. Correlation analysis was employed to find out the relationship between Father's occupation and the EI. The correlation coefficient (r) was found to be 0.283 . A positive and significant relationship has been demonstrated by this finding. Hence, hypothesis " $\mathrm{H} 1_{0}$ : There is no significant relationship between Father's occupation and EI of Omani university students" was rejected at 0.01 levels. The results indicate that the students whose fathers are engaged in business have a higher level of EI. The results are in line with previous studies such as De Wit \& Van Winden (1989) which found that father's occupation has an impact on the on the EI.

Gender. Correlation analysis was employed to find out the relationship between gender and the EI. The correlation coefficient (r) was found to be -0.296 . A negative and significant relationship has been demonstrated by this finding. Hence, hypothesis which states that " $\mathrm{H} 2_{0}$ : There is no significant relationship between gender and EI of Omani university students was rejected at 0.01 levels. Results imply that males have more inclination towards entrepreneurship than females. Results conform to previous literature findings on gender and entrepreneurship such as Crant (1996) which have also reported higher EI for male students.

Experience. The correlation analysis was employed to find out the relationship between Experience and the EI. The correlation coefficient (r) was found to be 0.674 . A positive and significant relationship has been demonstrated by this finding. Hence, hypothesis " $\mathrm{H} 3_{0}$ : There is no significant relationship between Experience and EI of Omani university students" was rejected at 0.01 level.

Results indicate that experience is an advantage for university students. As experience enables to have a better knowledge about business and also helps to build an associated network for entrepreneurship. The results are in line with previous studies such as Wang \& Wong (2004), which shows that the entrepreneurs create their companies after having worked in sectors close to the business sector of the new company where they acquired their skills and their experiences with the product. This is so because they possess a good knowledge about markets, technologies and industry.

Level of education. The correlation analysis was employed to find out the relationship between Educational levels and the EI. The correlation coefficient (r) was found to be -0.301 . A negative and significant relationship has been demonstrated by this finding. Hence, hypothesis " $\mathrm{H} 4_{0}$ : There is no significant relationship between the level of education and EI of Omani university students" was rejected at 0.01 level. Higher qualified students were found to have lesser EI. This observation was also found by Ghazali et al. (1995). One likely cause for this may be the rewarding career prospects of higher qualified students in public and private enterprises. Thus, it is unwarranted for them to start their own business and give up the benefits of salaried employment.

\section{Conclusions and recommendations}

The findings have implications for government, policy makers and universities. Firstly, the EI of Omani student is high and many desire to start their own businesses. In order to promote entrepreneurship in Oman students should be made aware of the various existing support and financing schemes for entrepreneurs being provided by the government. Secondly, demographic factors are found to have an influence on the EI. On comparing the correlation coefficient (r) value for the independent variables, experience was found to have the maximum correlation with EI. Therefore, policy makers should focus on ways to expose students to real life industry situations so that they may gain experience. Entrepreneurship can be promoted by focusing on methods to raise the EI among the university students such as introducing entrepreneurship course and making on job training a part of the course curriculum. This will give students a chance to get hands on experience and help in familiarizing them towards entrepreneurship. As female students have lesser EI than their male counterparts entrepreneurship courses should try to orient the mind-set of the female students towards entrepreneurship.

Dhofar University was the first university in Oman which established a center for entrepreneurship in order to build entrepreneurship culture in the region 
and Oman as well by putting the necessary educational plans for positive interacting with the development of the Omani economy by finding alternative ways to increase the national income and well-being of the society away from oil production. Other universities and higher education institutes in Oman can also establish entrepreneurship centres to promote entrepreneurship.

\section{Limitations and scope for further research}

The sample for research was restricted to the students of the Dhofar University in Salalah, Oman. Ideally, the responses should be taken from the different universities and colleges of Oman but due to paucity of time, geographical conditions and other reasons, the responses were taken from only one university. Also as the sample size is limited, the findings can be taken only as indicative results. Therefore, it is worth mentioning that the findings have to be compared and confirmed with a study with bigger samples size to get better accuracy.

The present study can be extended in several directions for further research. For example, it would be interesting to analyze whether students from Engineering faculty or say Commerce and Business faculty would have a higher EI than students of other faculties. Additionally, further research can be carried out to find the relationship between EI and actually becoming an entrepreneur.

\section{References}

1. Brown, R. (1990). Encouraging enterprise: Britain's graduate enterprise program, Journal of Small Business Management, 28 (4), pp. 71-77.

2. Crant, J.M. (1996). The proactive personality scale as a predictor of entrepreneurial intentions, Journal of Small Business Management, 34 (3), pp. 42-49.

3. Davidsson, P., Lindmark, L. \& Olofsson, C. (1995). Small firms, business dynamics and differential development of economic well-being, Small Business Economics, 7 (4), pp. 301-315.

4. Devine, T.J. (1994). Characteristics of self-employed women in the United States, Monthly Labor Review, 117 (3), pp. 20-34.

5. De Wit, G. \& Van Winden, F.A. (1989). An empirical analysis of self-employment in the Netherlands, Small Business Economics, 1 (4), pp. 263-272.

6. Fini, R., Grimaldi, R., Marzocchi, G.L. \& Sobrero, M. (2009). The foundation of entrepreneurial intention. Conference proceedings in Summer Conference, June 17-19, Frederiksberg, Denmark, Counseling and Development, 27 (3), pp. 136-152.

7. Ghazali, A., Ghosh, B.C. \& Tay, R.S.T. (1995). The determinants of self-employment choice among university graduates in Singapore, International Journal of Management, 12 (1), pp. 26-35.

8. Hakim, C. (1988). Self-employment in Britain: recent trends and current issues, Work, Employment \& Society, 2 (4), pp. 21-450.

9. Kolvereid, L. (1996). Organizational employment versus self-employment: reasons for career choice intentions, Entrepreneurship Theory and Practice, 20 (3), pp. 23-31.

10. Koh, H.C. (1996). Testing hypotheses of entrepreneurial characteristics: A study of Hong Kong MBA students, Journal of Managerial Psychology, 11 (3), pp. 12-25.

11. Kourilsky, M.L. \& W.B. Walstad. (1998). Entrepreneurship and female youth: Knowledge, attitudes, gender differences and educational practices, Journal of Business Venturing, 13, pp. 77-88.

12. Kristiansen, S. \& N. Indarti. (2004). Entrepreneurial intention among Indonesian and Norwegian students, Journal of Enterprising Culture, 12 (1), pp. 55-78.

13. Lerner, M. \& Yeoshua, H. (1996). New entrepreneurs and entrepreneurial aspiration among immigrants from the former USSR in Israel, Journal of Business Research, 36 (1), pp. 59-65.

14. Linan, F., Rodriguez-Cohard, J.C. \& Rueda-Cantuche, J.M. (2005). Factors affecting entrepreneurial intention levels. In 45th Congress of the European Regional Science Association, Amsterdam, pp. 23-27.

15. Magd, Hesham A.E. and Mark P. McCoy. (2014). Entrepreneurship in Oman: Paving the Way for a Sustainable Future, Procedia Economics and Finance, 15, pp. 1632-1640.

16. Matthews, C.H. \& Moser, S.B. (1996). A Longitudinal Investigation of the Impact of Family Background, Journal of small Business Management, Apr, 34 (2), pp. 29-43.

17. Mazzarol, T., Volery, T., Doss, N. \& Thein, V. (1999). Factors influencing small business start-ups: a comparison with previous research, International Journal of Entrepreneurial Behavior \& Research, 5 (2), pp. 48-63.

18. Othman, M.N., E. Ghazali et al. (2006). Graduate versus non-graduate entrepreneurs in urban Malaysia: Some insights into entrepreneurial personality, company and family background differences, Journal of International Business and Entrepreneurship Development, 3 (1/2), pp. 57-75.

19. Phan, P.H., P.K. Wong et al. (2002). Antecedents to entrepreneurship among university students in Singapore: Beliefs, attitudes and background, Journal of Enterprising Culture, 10 (2), pp. 151-174.

20. Reynolds, P.D. (1991). Sociology and entrepreneurship: concepts and contributions, Entrepreneurship Theory and Practice, 16 (2), pp. 47-70.

21. Schiller, B.R. \& Crewson, P.E. (1997). Entrepreneurial origins: A longitudinal inquiry, Economic inquiry, 35 (3), pp. 523-531. 
22. Scott, M.G. \& Twomey, D.F. (1988). The long-term supply of entrepreneurs: students' career aspirations in relation to entrepreneurship, Journal of small business management, 26 (4), pp. 5-13.

23. Shariq, M., Uddin M.A. \& Ahmad, M. (2016). Factors affecting entrepreneur's development in Oman, Corporate Ownership and Control Journal, 13 (2), pp. 66-70.

24. Stanworth, J., Stanworth, C., Granger, B., \& Blyth, S. (1989). Who becomes an entrepreneur? International Small Business Journal, 8 (1), pp. 11-22.

25. Stewart, W.H. Jr., Watson, W., Carland, J.C., Carland, J.W. (1999). A proclivity for entrepreneurship: a comparison of entrepreneurs, small business owners, and corporate managers, Journal of Business Venturing, 14 (2), pp. 189-214.

26. Timmons, J.A. (1994). New Venture Creation Entrepreneurship for the 21st Century. Irwin, Boston.

27. Tkachev, A. \& L. Kolvereid (1999). Self-employment intentions among Russian students, Entrepreneurship and Regional Development, 2, pp. 269-280.

28. Turker, D. \& Selcuk, S.S. (2009). Which factors affect entrepreneurial intention of university students? Journal of European Industrial Training, 3 (2), pp. 142-159.

29. Uddin, M.A., \& Khan, K. (2015). A Study of the Entrepreneurial Constrains in the Indian Manufacturing Sector, International Journal of Economics and Financial Issues, 5 (4), pp. 1055-1059.

30. Van de Ven, A.H., Schroeder, D.M. (1984). Designing new business startups: entrepreneurial, organizational, and ecological considerations, Journal of Management, 10 (1), pp. 87-107.

31. Veciana, J.M., M. Aponte et al. (2005). University students' attitudes towards entrepreneurship: A Two countries comparison, International Entrepreneurship and Management Journal, 1, pp. 165-182.

32. Wang, C.K. \& Wong, P.K. (2004). Entrepreneurial interest of university students in Singapore, Technovation, 24 (2), pp. $163-172$. 